\title{
Load Injected DC Current in Distribution Transformers: Investigation and Elimination
}

\author{
J. P. Karunadasa and H. M. A. I. Herath
}

\begin{abstract}
Due to heavy proliferation of power electronic and non-linear loads on a present day utility system, the DC current accumulated at the distribution transformer is significant. DC current shifts the operating point of the magnetization characteristic and hence causes the magnetizing current to exhibit severe asymmetry between positive and negative half cycles in magnitude and shape, owing to magnetic saturation. It affects the shape of input current and recreates a DC current at the input with magnitude even greater. This paper describes the work on influence of DC current on input current in a loaded transformer, and a system to divert DC current completely away from the transformer. Implementation was done with a specially designed current sensor and a fast responsive controlled current source. The later was implemented in power electronic with closed loop control. The work was challenging because measuring of small DC current superimposed with a large AC current was not straightforward, and also injecting a small DC current accurately against a large AC voltage was not straightforward. Both these challenges were successfully overcome and an extremely good DC current diversion system was developed. Details of the design and results of investigations are presented.
\end{abstract}

Keywords: DC cancellation, DC sensing, distribution transformer, load-injected DC current, magnetizing current, magnetic saturation, power quality

\section{Introduction}

POWER electronic based loads, grid-tie inverters and other non-linear loads in the present day utility system creates small DC current component on top of their normal AC current. Proliferation of such loads and inverters results in a significant net DC current accumulated at the secondary of the distribution transformer. This accumulated DC current, when it is comparable to the magnetizing current of the transformer introduces severe power-quality distortions in the system. In particular, DC current in the secondary shifts the transformer operating point on the magnetization curve forcing alternative halfcycles to undergo magnetic saturation, and thereby leading to severe asymmetry between positive and negative half cycles of the magnetization current, both in magnitude and shape. More importantly, the input current then starts carrying a DC current component with magnitude even higher than the DC current that was present in the secondary [1]. Further, transformer itself can undergo overheating, increased power losses and reduced lifespan etc. In addition to these problems, the accumulated DC current can cause corrosion in underground equipment, errors in metering, malfunctioning of protective equipment, overheating of other grid connected equipment such as capacitor banks and AC machines etc.[3] -[6].
At the outset, to address the DC current issue in the utility system, the individual equipments that are likely to contribute DC need to be regulated through appropriate standards. For example, grid-tie inverter which is one of the influential equipments that injects noticeable DC current is regulated by standards given in Table 1. Secondly, to minimize the DC injection to the utility, the DC contributing equipments need to have adopted a proper method of interconnection with the utility, For examples, three methods of interconnection have been proposed in the literature for connecting grid-tie inverters with the utility, namely line frequency transformer interconnection, high frequency transformer interconnection and transformerless interconnection [3],[4],[7]-[10], [12], each having its own advantages and disadvantages.

Line frequency transformer is large, heavy and forms a substantial cost in the grid connected system and it contributes to significant power losses, lowering inverter efficiency by about 1$2 \%$ [3], [7].

Eng. (Prof.) J. P. Karunadasa, C. Eng., MIE(SL), B.Sc. Eng. (Hons) (Moratuwa), MSc (Manchester), PhD (Manchester). Associate Professor in Electrical Engineering, University of Moratuwa, Sri Lanka. Email: karu@elect.mrt.ac.lk.

Eng. (Ms) H. M. A. I. Herath, C. Eng., MIE(SL), B.Sc. Eng. (Hons) (Ruhuna), MSc. (Moratuwa), Lecturer, General Sir John Kotelawala Defence University, Rathmalana, Sri Lanka. Email: ayeshaih@gmail.com. 
Table 1- Limits of DC current injection permitted by different countries for grid-tie inverters (LV system)

\begin{tabular}{|c|c|c|}
\hline Country & Standard & $\begin{array}{l}\text { Maximum permitted } \\
\text { DC current }\end{array}$ \\
\hline $\begin{array}{l}\text { United } \\
\text { Kingdom }\end{array}$ & ER G83/1 & $\begin{array}{l}0.25 \% \text { of rated } \\
\text { current of the } \\
\text { inverter }\end{array}$ \\
\hline Australia & AS 4777.2 & $\begin{array}{l}0.5 \% \text { of rated current } \\
\text { of the inverter or } \\
5 \mathrm{~mA}, \text { whichever } \\
\text { greater }\end{array}$ \\
\hline USA & $\begin{array}{l}\text { IEEE 929- } \\
2000 \\
\text { IEEE } 1547\end{array}$ & $\begin{array}{l}0.5 \% \text { of rated current } \\
\text { of the inverter } \\
0.5 \% \text { of rated current } \\
\text { of the inverter }\end{array}$ \\
\hline Switzerland & IEC 61727 & $\begin{array}{l}1 \% \text { of rated current } \\
\text { of the inverter }\end{array}$ \\
\hline Germany & $\begin{array}{l}\text { DINVDE } \\
0126-1-1\end{array}$ & $\begin{array}{l}\text { 1A (Total injection) } \\
\text { [States in the case of } \\
\text { DC current injection } \\
\text { greater than } 1 \mathrm{~A} \text {, } \\
\text { disconnection is } \\
\text { mandatory in } 0.2 \mathrm{~S} \text { ] }\end{array}$ \\
\hline
\end{tabular}

Transformerless interconnection proposes a DC blocking capacitor in the inverter output but this requires a large and expensive AC capacitor [3]. Another transformerless interconnection proposes a half bridge inverter which is inherently blocking DC but this requires a DC link voltage twice the inverter output voltage, and correspondingly higher rating of inverter components, adding to higher cost and reduced system efficiency [3],[8]. High frequency transformer interconnection does not guarantee DC component cancellation and has reduced efficiency/cost ratio due to several stages [10].

The sure option for eliminating the influence of DC current in the distribution transformer is to divert DC current away from the transformer. This can be done by using a power electronic converter in parallel with the transformer secondary to divert the DC current arriving at the transformer so that no DC current enters in to the secondary of the transformer. The converter must be supported with closed loop control of current to act as a current source of magnitude and shape exactly matching the incoming DC current. This requires an accurate current sensor that can measure small DC current superimposed with a large AC current. Hall-element based current sensors are not suitable for this purpose due to the noise and drifts of the sensors which make the extraction of DC current information very difficult and inaccurate. A good option is to sense the DC voltage produced by the DC current in the secondary-resistance. One arrangement proposes to take the full voltage across the secondary and extract the DC part by removing the $\mathrm{AC}$ part with an equal and opposite $\mathrm{AC}$ component induced through an instrument transformer [4]. However, the instrument transformer itself is sensitive to DC current and also an ideal cancellation of the AC component is not feasible, hence resulting in significant measuring errors. Another proposal suggested to use a small instrument transformer across the secondary and to use its magnetizing current to extract the information of DC voltage by processing the asymmetry between positive and negative half-cycles [10], [11]. This method is relatively complex to implement and the accuracy depends largely on the methods used to acquire and process the magnetizing current signal.

This paper presents the work of a design and implementation of a total DC current diverting system at the secondary of a distribution transformer. The DC current sensor used in this paper has a specific design not involving instrument transformers. It is a voltage based sensor with a special AC cancellation technique. The sensor is found to be performing exceptionally well on a $400 \mathrm{~V}$ AC secondary with a superimposed small DC voltage component around $1.25 \mathrm{~V} \mathrm{DC}$. The power converter used in the implementation is an H-bridge converter, operated in current control mode. Current control is done in closed loop and the controller is designed after developing the model for the entire system. Current diversion is done separately from individual phases and the details presented are for the system of one phase only. Simulations are done in MATLAB/Simulink environment and the results prove the successfulness and the effectiveness of the proposed method.

\section{Measured DC Current in a Sample Distribution System}

To ascertain the order of DC current in the present day distribution systems, current measurements were done at the secondary of an $11 \mathrm{kV} / 400 \mathrm{~V}, 400 \mathrm{kVA}, 50 \mathrm{~Hz}$ three-phase distribution transformer feeding a significant count of personal computers and electronic equipment among other loads. Measurement was done using the FLUKE 435 Power Quality Analyzer. Figure 1 gives a screen-shot of basic $\mathrm{AC}$ values and Figure 2 gives the spectrum of currents which indicates DC currents of $1.1 \mathrm{~A}$, 1.5 A and 1.4 A in three phases, which are of the order of $10 \%$ of the magnetizing current for the 
transformer. This is a significant level of DC current for the transformer.

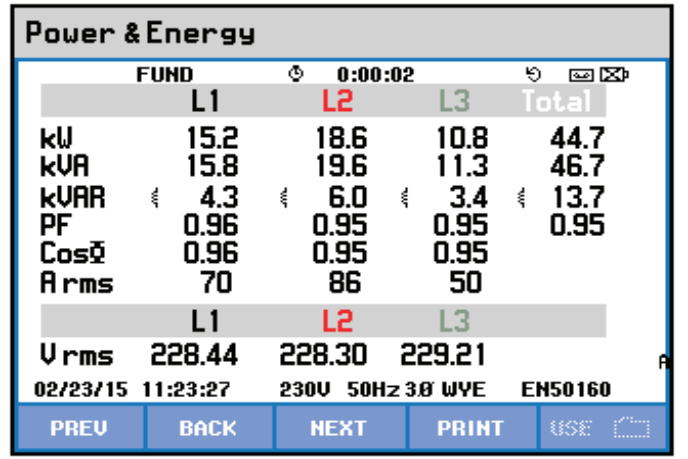

Figure 1- Screen shot of Power Analyser on AC values at the transformer secondary [1]

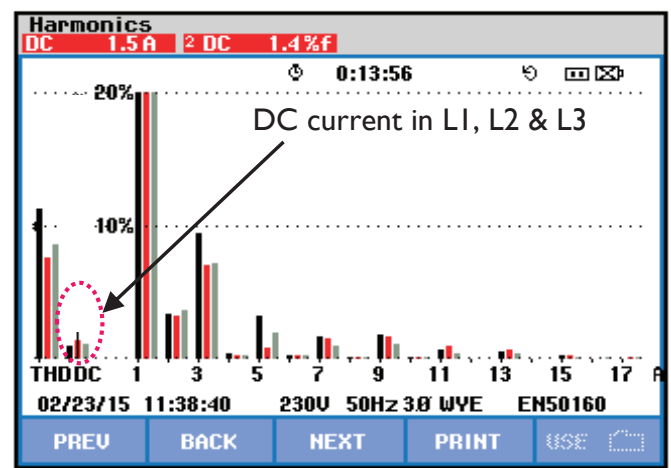

Figure 2- Current spectrum at the transformer secondary [1]

\section{Effects of DC Current on the Operation of a Transformer}

To demonstrate that the DC current circulating through the secondary of a transformer create significant distortions and asymmetries between the positive and negative half cycles of the input (primary) current waveform a series of laboratory tests were conducted on a singlephase transformer, rated at $50 \mathrm{~Hz}, 230 / 400 \mathrm{~V}, 4$ kVA.

3.1 Input current on no-load in normal operation

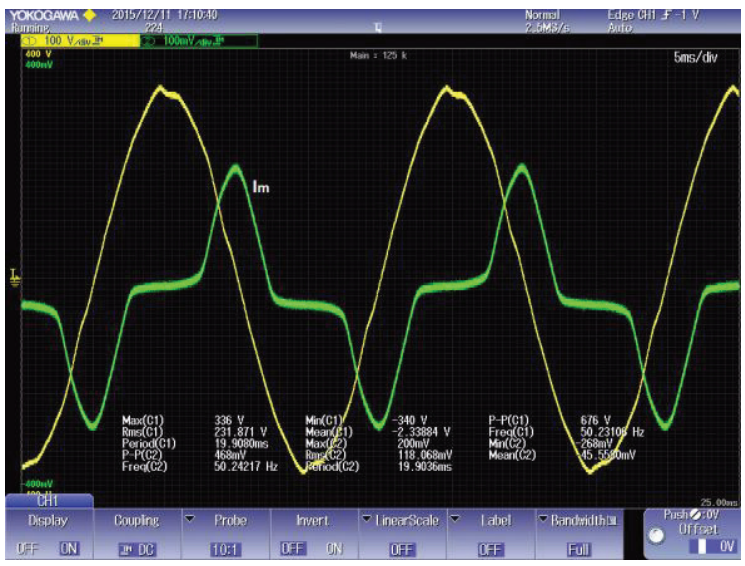

Figure 3- Tested input current on no-load at rated input voltage [1]
Figure 3 shows the input current measured at rated input voltage on LV side with $\mathrm{HV}$ side open. This current is mainly the magnetizing current drawn by the transformer. Waveform complies with the theoretical expectation having significant 3rd harmonic component and its positive and negative half cycles are similar implying symmetrical magnetization.

\subsection{Input current on load}

Figure 4 shows input current measured at $90 \%$ full load (resistive) on $\mathrm{HV}$ side. Current waveform is now sinusoidal because the magnetizing current is only a small fraction of the sinusoidal load-current.

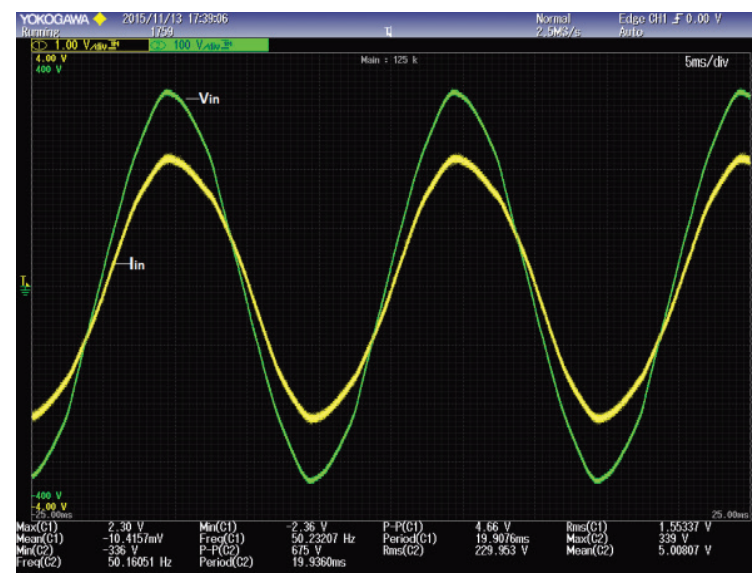

Figure 4- Tested input current at $90 \%$ load (resistive) at rated input voltage [1]

\subsection{Input current on load with heavy DC} current injection

Figure 5 shows the input current at $90 \%$ full load (resistive) on HV side with a superimposed DC current amounting to $35 \%$ full load current. This is a heavy DC current unlikely to occur in practice but consciously chosen to magnify the effects. The waveform clearly shows excessive distortions inflicted on the waveform. The negative peak of the input current waveform now occurs just about $90^{\circ}$ ahead of the positive peak and this is purely a magnetizing current peak. Its value has now reached staggering 38.4 A from its nominal value of $2.6 \mathrm{~A}$ in Figure 3. The positive peak is almost unchanged (21.5A) which is determined purely by the load. This behavior is in complete agreement with the theoretical predictions. The DC current injected at the secondary lowers the operating point of the iron core in the flux current characteristic, pushing the negative half cycle of flux deep in to saturating region resulting in a large negative peak of magnetizing current. The amplitude of this negative peak of magnetizing current is well above the negative peak of the load related input 
current. Thus the negative peak of the resultant input current occurs right at the location of the same of the magnetizing current, which is $90^{\circ}$ behind the negative peak of the voltage. The positive peak of the magnetizing current does not change much as the positive half of the flux waveform is now virtually inside the linear portion of the characteristic, and remains near 2.6 A. Therefore, the resultant input current waveform retains its positive peak at the same location of the load related current, which is coinciding with the positive peak of voltage, with almost the same value of $21.5 \mathrm{~A}$. Thus, the phase angle shift between the negative and positive halves of the resultant input current waveform becomes nearly $90^{\circ}$. DC current injection for this test was done by way of connecting a diode in series with the load in the secondary. This is the reason for not having the part of input current waveform in phase with the negative half cycle of voltage.

Input voltage waveform is also now showing some distortions, especially a dip in the value near the positive going zero crossing of the waveform. This is mainly due to the voltage drop in the supply side impedance. This introduces asymmetry to the waveform and thereby a notable $2^{\text {nd }}$ harmonic component.

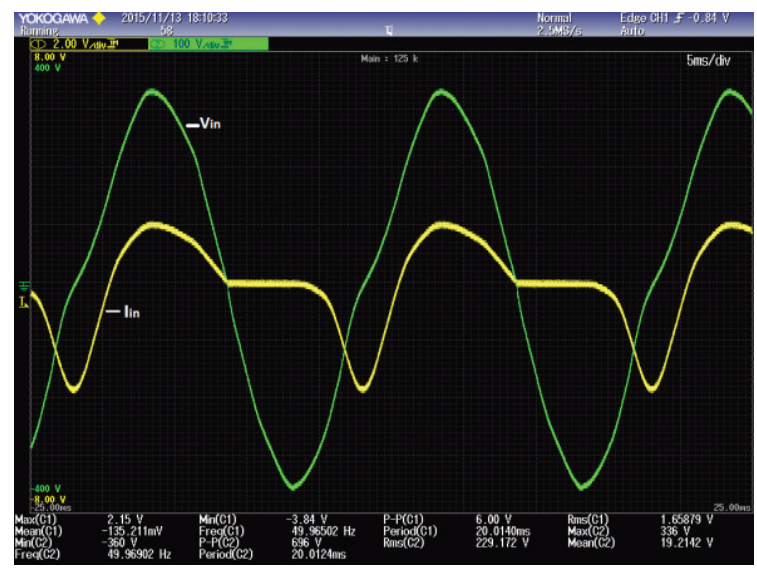

Figure 5- Tested input current with 35\% DC current at $90 \%$ load (resistive) at rated input voltage [1]

\subsection{Input current on load with a small DC} current injection

Figure 6 shows the input current at $90 \%$ full load (resistive) on HV side with a superimposed DC current amounting to $10 \%$ of rated current. Consciously, the DC current was injected with the negative polarity to cause an opposite shifting of the magnetic operating point and saturation in the positive half cycle.

The positive half cycle of current is now "broadened" beyond the zero-crossing of the voltage but the negative half cycle remains relatively unchanged. This behaviour of current is again due to the asymmetry of the magnetizing current, caused by the injected DC current. Now the magnetic operating point is shifted up on the flux-current characteristic and hence the positive half cycle of flux is driven in to hard saturation, resulting in a very high positive peak of magnetizing current. Although the DC current injected was only $10 \%$ rated current the saturation has raised the positive peak of the magnetizing current from its nominal value of $2.6 \mathrm{~A}$ (see Fig.3) to about $18 \mathrm{~A}$, as seen in the current waveform at the point $90^{\circ}$ behind of the voltage peak. The summation of large positive peak of magnetizing current and the positive peak of load current, which is inphase with the voltage, results in a broader positive half cycle of the input current. The negative half cycle of input current remains as of the load related current because the negative peak of the magnetizing current is only below $2.6 \mathrm{~A}$, which is too small compared to the load related current peak of $23 \mathrm{~A}$.

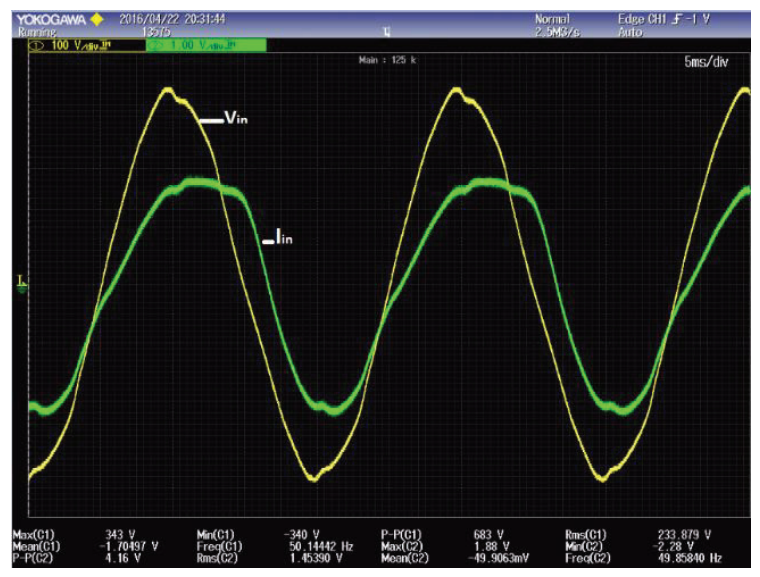

Figure 6- Tested input current with 10\% DC current at $90 \%$ load (resistive) at rated input voltage [1]

\section{Proposed System of Eliminating DC Current at the Point of Common Coupling (PCC)}

Figure 7 gives an overview of the proposed system of eliminating DC current in each phase of the transformer. DC current created by the consumer-loads is sensed at the transformer secondary by a DC-current sensor and the information is directed to a closed loop current controller, which steers a power electronic converter with PWM control to deliver an equal DC current to the load. This way, the DC current circulating in the transformer secondary is eliminated. 


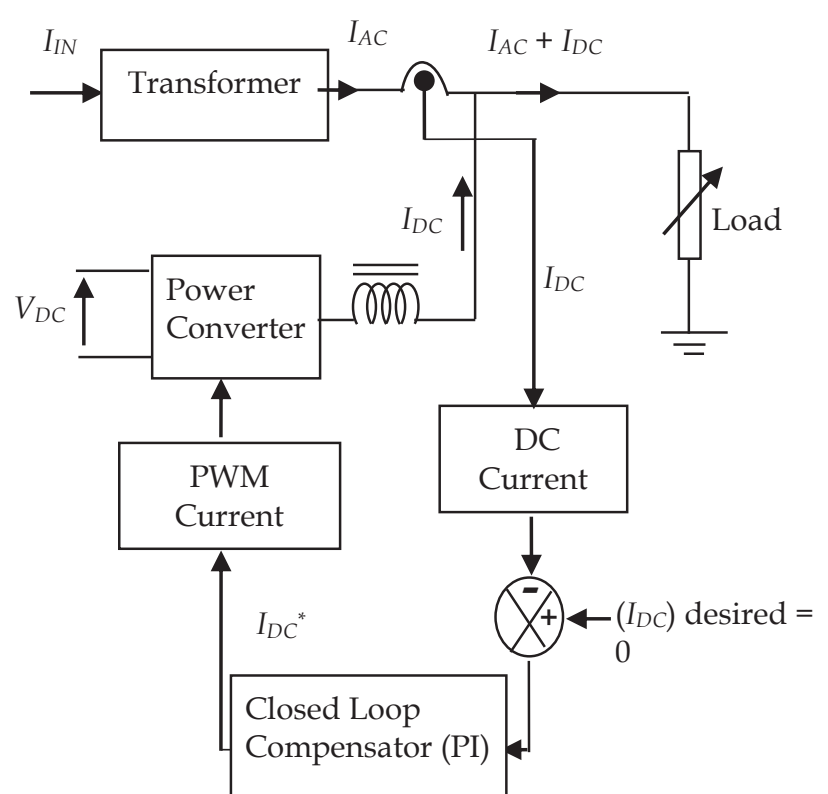

Figure 7- Proposed arrangement of DC current cancellation system at PCC

\subsection{Current Sensor}

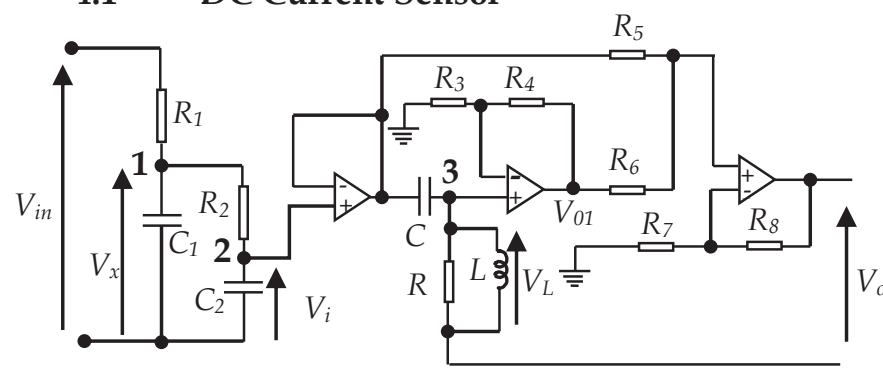

Figure 8- DC current detector circuit

Figure 8 shows the arrangement of the current sensor. Front end is a two-stage RC-divider to attenuate the $\mathrm{AC}$ voltage component in the measuring-voltage. Body resistances of the capacitors create a small attenuation of the DC component but this is predictable and can be accommodated in the design. AC voltage component present in the output of the $\mathrm{RC}$ divider is then removed by the AC cancellation circuit that has an RLC filter at its center. The DC component is finally taken through the gainsetting stage to restore the path attenuations. Figure 9 illustrates the functionality of the current sensor.

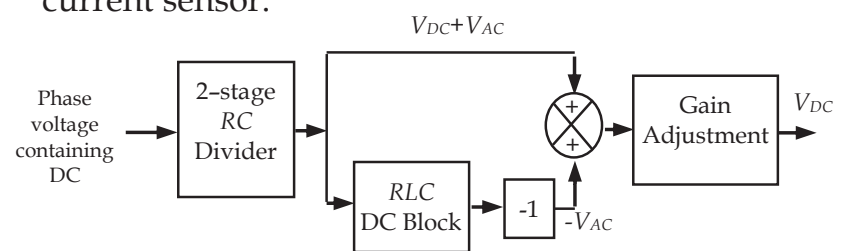

Figure 9- Functionality of DC current detector
The transfer function between Vin and Vo of the current sensor is given in equation 1[2].

$$
\frac{V_{o}}{V_{i n}}=\frac{1115\left(1690 S^{2}+166.7 S+166666666.7\right)}{\left(S^{2}+166.7 S+166666666.7\right)\left(3 S^{2}+173.8 S+1108.1\right)}
$$

\subsection{Power Electronic Converter}

The function of power electronic converter is to inject cancelling DC current in to the transformer secondary, as requested by the closed loop current controller. Injection is done phase-wise and hence the standard H-bridge configured power converter arrangement, shown in Figure 10 , was selected. To ensure satisfactory injection of current against the $\mathrm{AC}$ voltage present at the transformer secondary, the DC voltage input to the converter should be sufficiently greater than the peak value of the AC voltage at the secondary. The 1-phase transformer used in this study had a secondary voltage of $400 \mathrm{~V}$ (rms) and hence $660 \mathrm{~V}$ (DC) voltage input was selected to give an adequate margin. An inductor $L$ between the output of the converter and the transformer secondary is a must to enable the control of current.
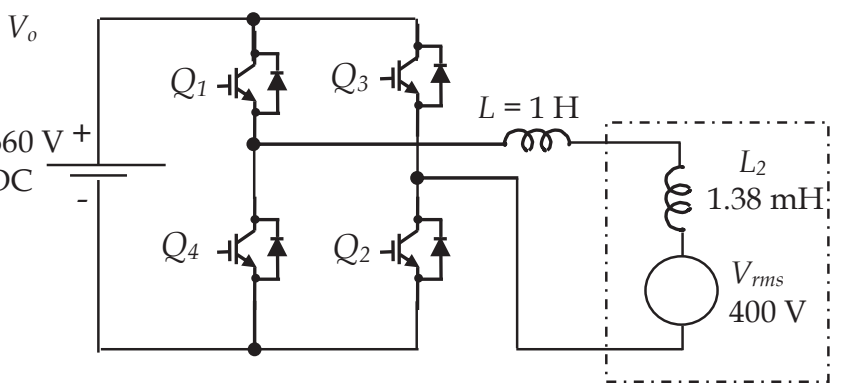

Transformer Secondary

Figure 10- Circuit of Power Electronic Converter

At any instant of time, switching Q1 \& Q2 causes the current I to rise, and switching Q3 \& Q4 makes the current to fall. Minimum switching frequency occurs at the positive or negative peak of the AC voltage waveform and maximum switching frequency occurs at the zero crossing points of the AC voltage waveform. This converter operates at $4.6 \mathrm{kHz}$ and $16.7 \mathrm{kHz}$ as minimum and maximum switching frequencies. Transfer function of the power electronic converter was derived considering action of the converter with hysteresis current control in converting a step input at the current controller 
to the actual current injected to the transformer secondary.

Figure 11 shows the schematic of the hysteresis current controller, power electronic converter, and the transformer secondary. Current feedback from the output of the power converter to the hysteresis-controller was made with a gain of 0.25 because the actual current in the transformer secondary was sensed (by the current sensor) as a voltage drop across the 0.25 $\Omega$ secondary-resistance of the transformer.

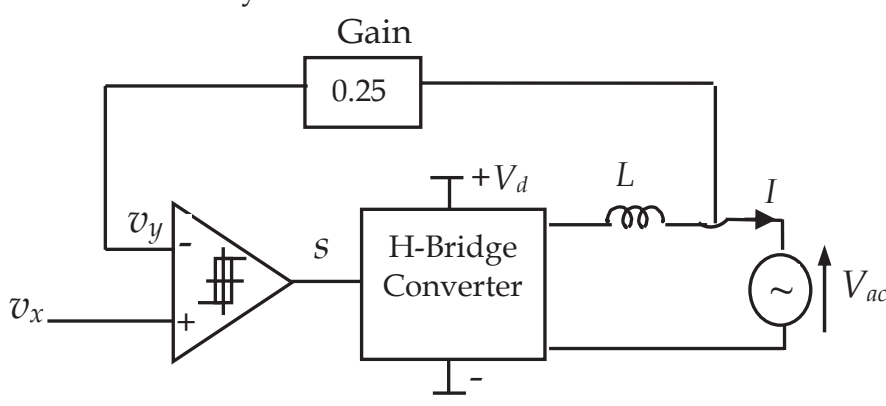

Figure 11- Schematics of Power Electronic Converter with Hysteresis Controller function to derive transfer function

$v_{x}=$ Input to the current controller

$v_{y}=$ Feedback of output current at the current controller

$S=\quad$ Switching signal to the H-Bridge

$\mathrm{I}=$ Current injected to transformer secondary, by the H- Bridge

Transfer function of the current controller and power electronic converter was derived with reference to step response between $V_{x}$ and $V_{y}$. The resulting transfer function is given in equation 2 .

$F(S)=\frac{1320}{(S+1320)}$

\subsection{Closed Loop Compensator}

Closed loop compensator is a crucial unit in the entire DC current elimination strategy to hold the DC current flowing in the transformer secondary at zero, irrespective of DC current returned by the load.

Main functions to be served by the compensator are:

(i) To guarantee zero steady-state DC current in the transformer secondary.

(ii) To settle transient DC current fast in the transformer secondary.

(iii) To restrict peak-overshoot of transient DC current within range in the transformer secondary
Figure 12 shows the schematic of the system from a control point of view. The set-input to the closed-loop current controller is zero. Feedbacksignal out from the current sensor contains a disturbance in the form of a transient, caused by the secondary AC voltage component, which need not be passed on to the closed loop compensator. Therefore, a signal limiter was placed on the output of the current sensor to clip out the disturbance component. The limiter was set at $\pm 3 \mathrm{~V}$ which was found adequate to stop the disturbance without significantly affecting the speed of response.

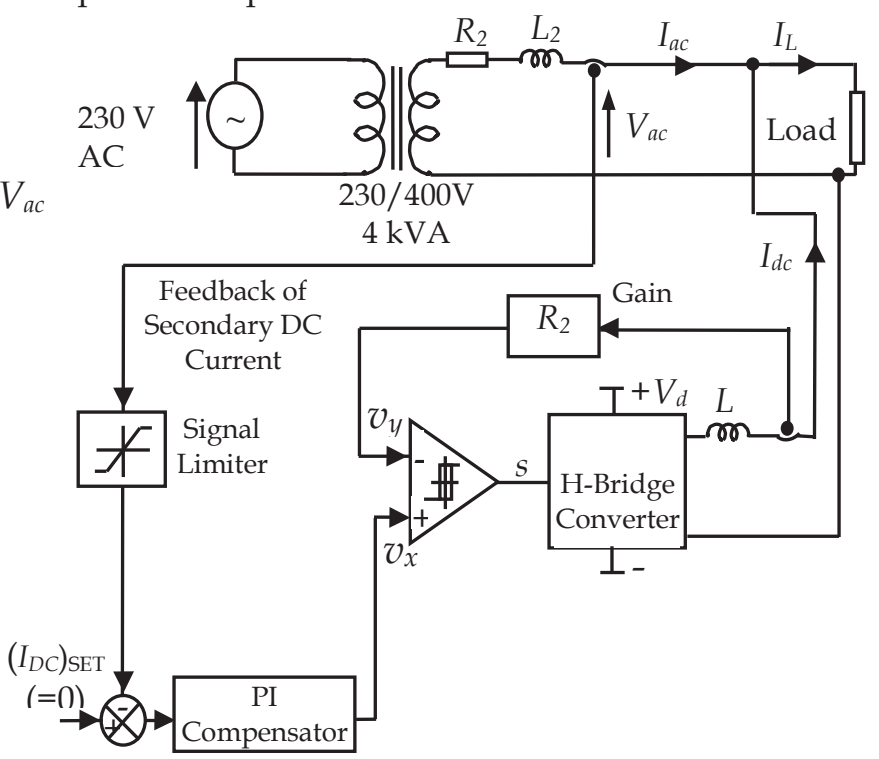

Figure 12- Details of Feedback current controller

As long as there is a net DC current in the transformer secondary, the DC current sensor output has a non-zero value, and accordingly integral compensator output keeps rising. The power electronic converter which converts compensator output to DC current, thus, keeps raising the DC current injected in to the transformer. Transformer secondary takes the difference between the converter-injected DC current and the load-produced DC current, which becomes zero when the injected DC current matches the DC current produced by the load. At this instant, the current sensor output becomes zero and the integral compensator output stops further increase. Thus, the control action stops, and the secondary DC current continues to remain at zero. Subsequently, if changes occur in the load-produced DC current, the closed loop controller will act and respond appropriately to bring the DC current in the transformer secondary back to zero. 
Figure 13 shows the transfer function blockdiagram of the closed loop current control system. AC voltage present at the transformer secondary acts as a disturbance input to the current sensor and it is modelled accordingly. This is a $50 \mathrm{~Hz}, 400 \mathrm{~V}$ (rms) disturbance input.

$$
\begin{aligned}
& \left(\sqrt{2} V_{r m s} \sin \omega t\right)=\left(\frac{\sqrt{2} \omega s}{s^{2}+\omega^{2}}\right) \frac{V_{r m s}}{s}=D(s) \frac{V_{r m s}}{s} \\
& D(s)=\left(\frac{\sqrt{2} \omega s}{s^{2}+\omega^{2}}\right)=\left(\frac{444.29 s}{s^{2}+98696}\right)
\end{aligned}
$$

A value for the integral controller gain $K_{i}$ was obtained by simulating the closed-loop control system model given in Figure 13. A higher value of integral-gain lowered settling-time but raised peak-overshoot of the injected current; opposite happens when integral-gain was lowered. Gain values 1, 2 and 3 all found acceptable, and gain of 2 was selected. Corresponding settling time is about 3.0 second and response peak is $2.5 \mathrm{~A}$ for a step input of load DC current.

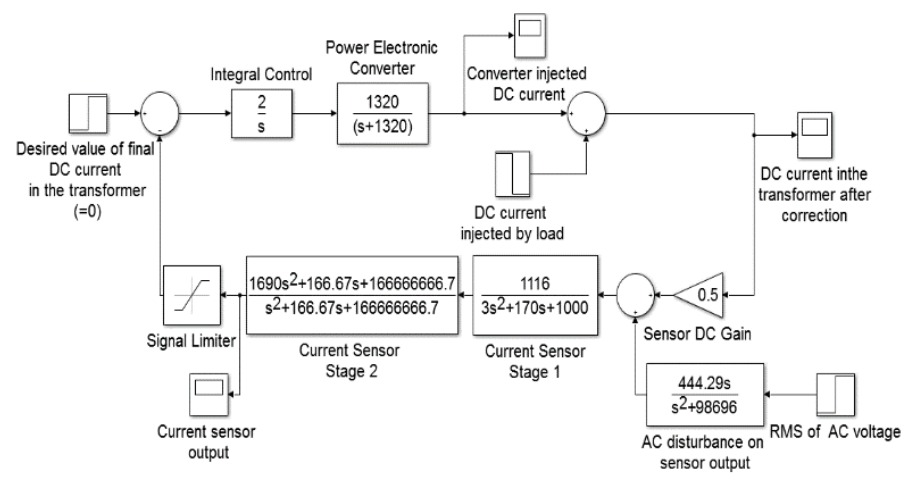

Figure 13- Transfer function block diagram of feedback controller

\section{Simulations}

\subsection{Response of the current sensor}

Response of the current sensor was tested by simulating the sensor in MATLAB with input containing a small DC voltage superimposed with $400 \mathrm{~V}$ AC voltage. Figure 14 shows the simulation model. It was observed that the sensor output is zero when the DC component at the input is zero despite the presence of steady AC voltage of $400 \mathrm{~V}$. Figure 15 shows the step response due to $1.25 \mathrm{~V}$ DC input with steady AC voltage of $400 \mathrm{~V}$. It clearly shows that the sensor produces its output for the DC component only with a response time below 0.5 s. Figure 16 shows the response of the sensor for simultaneous step inputs of $1.25 \mathrm{~V} \mathrm{DC}$ and $400 \mathrm{~V}$ AC. The response now shows an inrush transient of near $10 \mathrm{~V}$ peak created by the step AC voltage. This transient also disappears within $0.5 \mathrm{~s}$ leaving a steady state response of $1.25 \mathrm{~V}$ corresponding to the DC input. In the final system, a signal limiter at $\pm 3 \mathrm{~V}$ is used on the output of the current sensor to clip this type of inrush transients, which may occur due to initial switching or fluctuations in AC voltage, before passing the sensor output to the DC current injection system, without affecting the DC response (which is well within $\pm 3 \mathrm{~V}$ ).

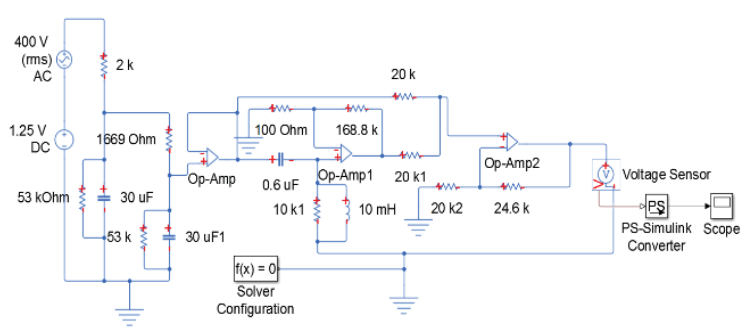

Figure 14- MATLAB simulation model of the current sensor

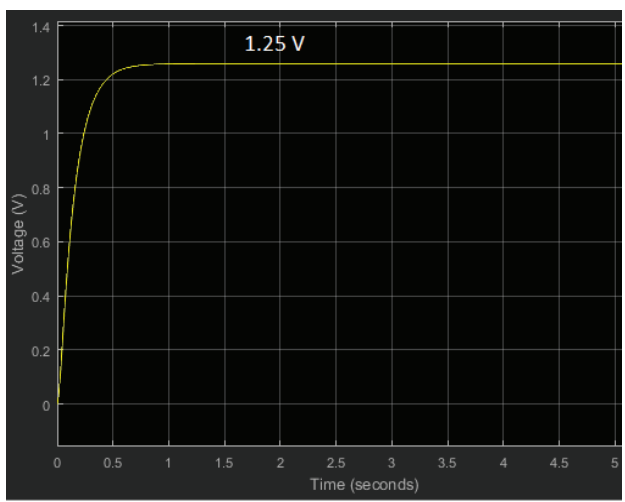

Figure 15- Response of current sensor for step DC voltage input of $1.25 \mathrm{~V}$ on top of steady $400 \mathrm{~V}$ AC voltage

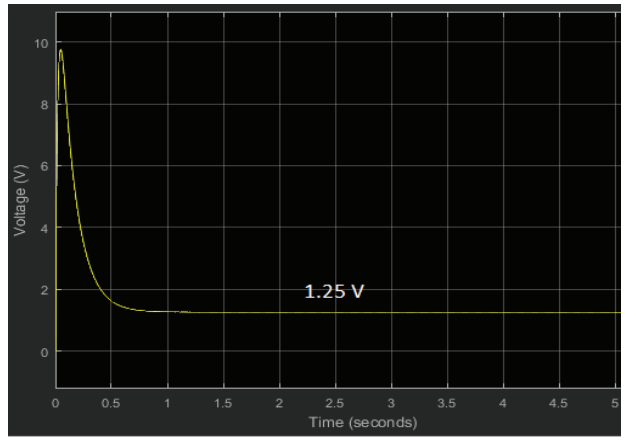

Figure 16- Response of current sensor for simultaneous 1.25V DC step and $400 \mathrm{~V}$ AC step

\subsection{Response of the Power Electronic} Converter

Current-injecting response of the power electronic converter with hysteresis current control was tested by simulating the converter, current controller and the transformer in 
MATLAB. Figure 17 shows the simulation model. Figure 18 shows the response of output current $\left(\mathrm{v}_{\mathrm{y}}\right)$ for a step input $\left(\mathrm{v}_{\mathrm{x}}\right)$ of magnitude $2 \mathrm{~V}$ to the hysteresis current controller. The AC response clearly shows that the output current is having approximately linear-building transient followed by constant current sustained by the action of hysteresis current controller. Halfwidth of hysteresis current controller was set at $10 \mathrm{mV}$.

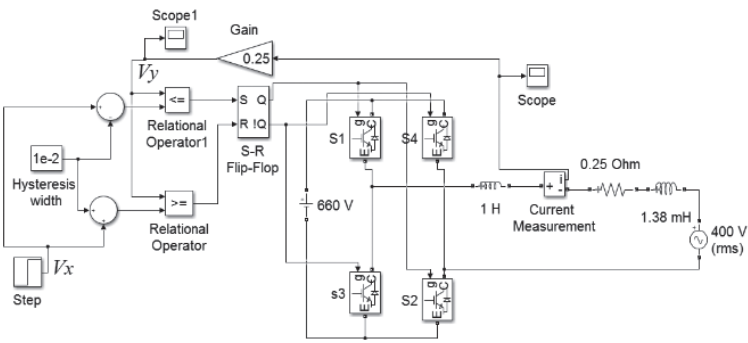

Figure 17- MATLAB simulation model of Converter, hysteresis Current controller and transformer

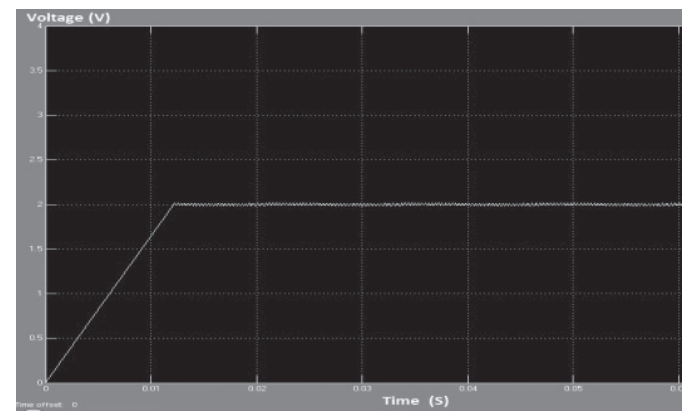

Figure 18- Step response of output current of the power electronic converter

\subsection{Overall Performance of the Current Elimination System}

Overall performance of the complete current elimination system was investigated by simulating the final system in MATLAB for different levels of DC current created by loads. The following representative cases were investigated by simulation, and in each case the elimination of DC current component from the transformer secondary was found perfect.

a) Case of $40 \%$ DC current in the load produced by half wave rectification of load current

Figure 19 shows the schematic of the system that was simulated. A series combination of $45 \Omega$ resistive load and a diode on the transformer secondary created a DC current, approximately $40 \%$ (4A) of rated rms current (10 A rms) of the secondary.

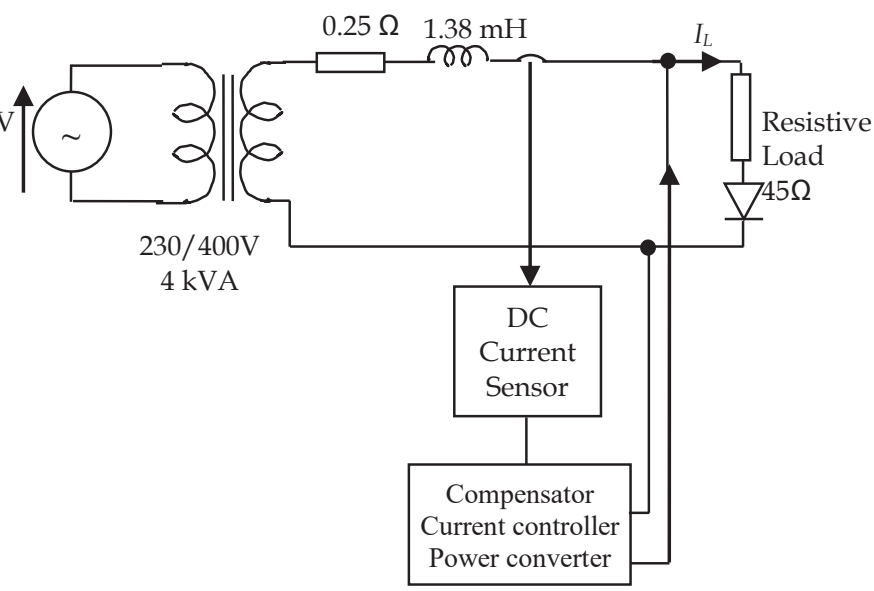

Figure 19- System schematic for $40 \%$ DC current in the load produced by half wave rectification of load current

Figure 20 shows the current waveform in the load, which is the half-wave rectified current waveform with a mean value equal to $4 \mathrm{~A}$. Figure 21 shows the output of the DC current sensor (same as the DC current circulating in the transformer secondary) which, due to the action of the DC current eliminating system has come to zero after a brief transient of less than 2 seconds. Figure 22 shows the DC current injected to the load by the power electronic converter which is settled at $4 \mathrm{~A}$ after the brief transient. It should be noted that, as stated before, the transient observed in the current sensor output is an initial inrush caused by the sudden application of AC voltage at the sensor input. The transient observed in the DC current injected to the load is partly due to the inrush of the sensor output but its amplitude is much lower due to the action of the current limiter. Figure 23 shows the final current in the transformer secondary, which is the rectified current waveform but without the DC component of $4 \mathrm{~A}$.

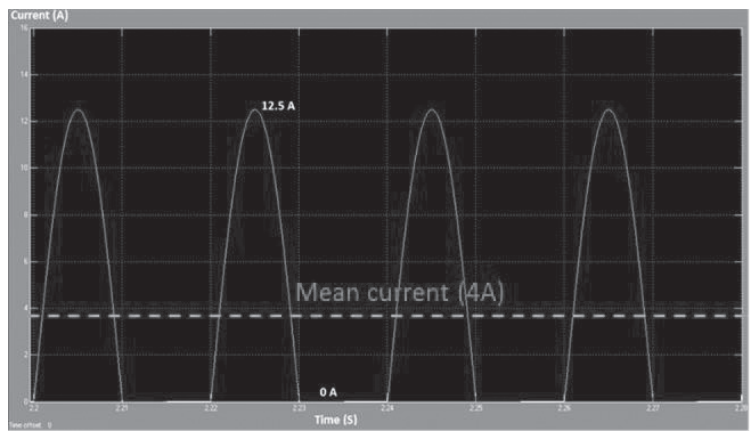

Figure 20- Half-wave rectified load current waveform 


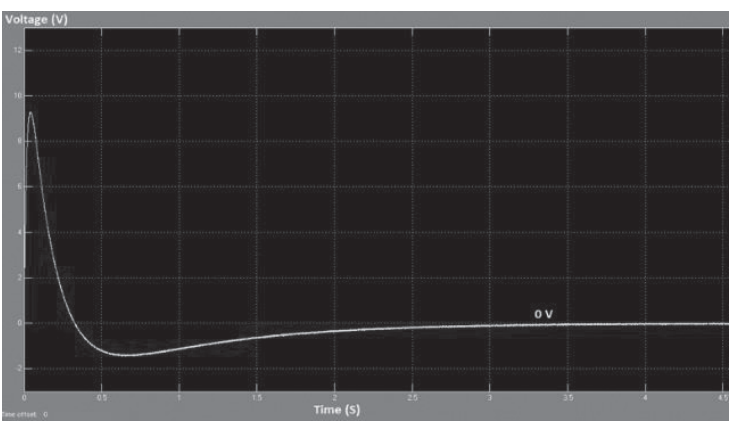

Figure 21- Output of the DC current sensor

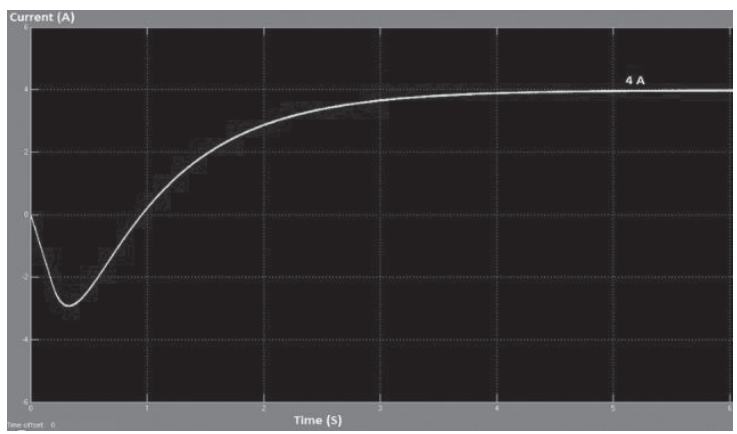

Figure 22- DC current injected to the load by the power electronic converter

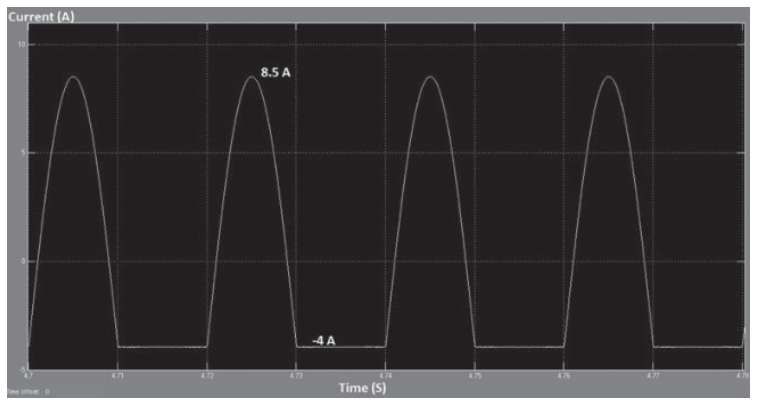

Figure 23- Final current in the transformer secondary

It can be observed that the waveform in Figure 23 is same as that in Figure 20 but now shifted down by $4 \mathrm{~A}$, indicating the removal of $\mathrm{DC}$ component.

b) Case of $10 \%$ DC current in the load produced by half-wave rectification of part of the load current

Figure 24 shows the schematic of the system that was simulated. A series combination of $170 \Omega$ resistive load and a diode on the transformer secondary created a DC current, approximately $10 \%$ of rated rms current of the secondary. The $58 \Omega$ resistive load created the AC component of load current, nearly $80 \%$ full load.

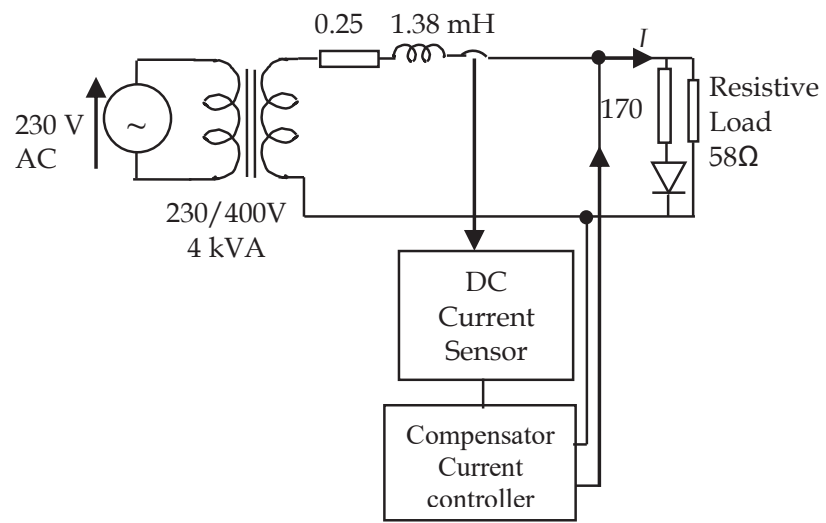

Figure 24- System schematic for 10\% DC current in the load produced by half wave rectification of part of the load current

Figure 25 shows the current waveform in the load, which has a 13 A positive peak and -9.7 A negative peak, with a mean value of $1 \mathrm{~A}$. Figure 26 shows the output of the DC current sensor (i.e. DC current circulating in the transformer secondary) which, due to the action of the DC current eliminating system has come to zero after a brief transient lasting about 1 second. Figure 27 shows the DC current injected to the load by the power electronic converter which is settled at $1 \mathrm{~A}$ after the brief transient. Figure 28 shows the final current in the transformer secondary, which is the load current waveform without the DC component of $1 \mathrm{~A}$.

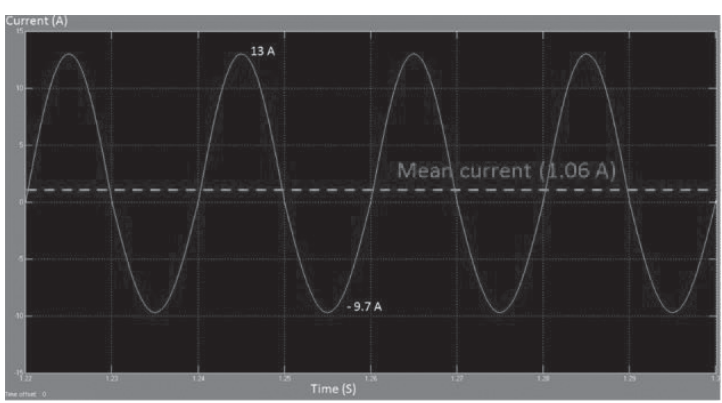

Figure 25- Load current waveform with 10\% DC on top of $80 \% \mathrm{AC}$

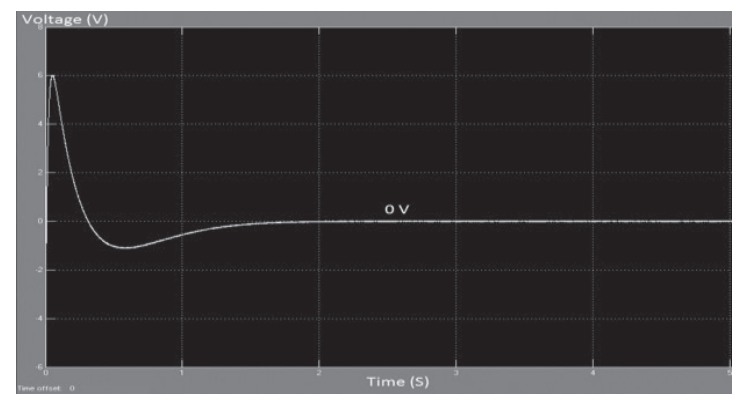

Figure 26- Output of DC current sensor 


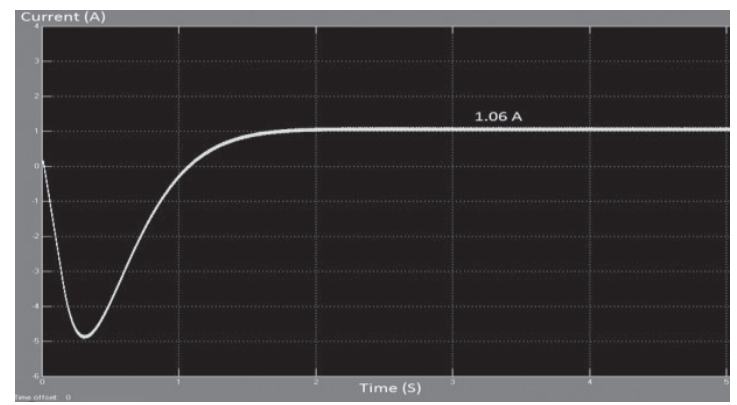

Figure 27- DC current injected to load by the power electronic converter

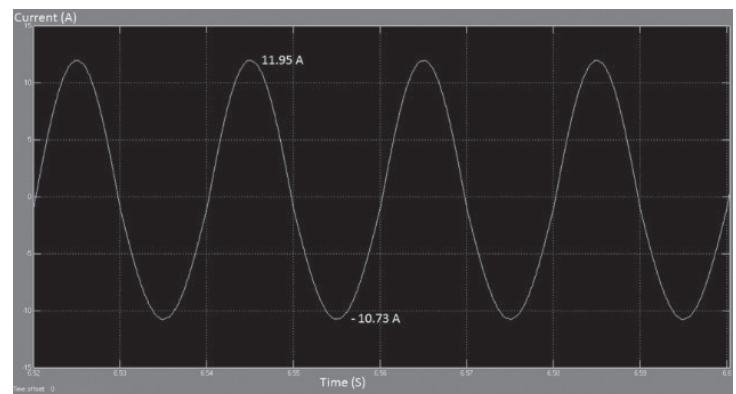

Figure 28- Final current in the transformer secondary

It can be observed that the current waveform in Figure 28 is same as that in figure 25 but now shifted down by $1 \mathrm{~A}$, indicating the removal of DC component.

c) Case of $1 \mathrm{~A}$ step DC current in the load produced by an ideal DC source at the load

Figure 29 shows the schematic of the system that was simulated. The $45 \Omega$ resistive load established $90 \%$ load current, and the ideal DC current source introduced step 1 A DC current in to the load. Figure 30 shows the current waveform in the load, which has a $13.4 \mathrm{~A}$ positive peak and -11.4 A negative peak, with a mean value of $1 \mathrm{~A}$.

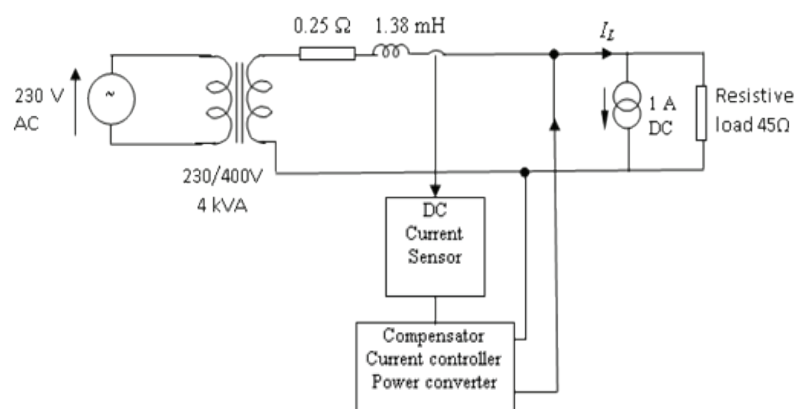

Figure 29- System schematic for 1A step DC current in the load produced by an ideal current source

Figure 31 shows the output of the DC current sensor. It can be observed that the sensor response has now gone to $-45 \mathrm{~V}$ at the beginning. Initially, 1A step current passes entirely through the $45 \Omega$ load resistance as the inductive secondary winding acts as an open circuit for the step-change. So, the resulting $45 \mathrm{~V}$ DC developed across the load has been detected by the sensor. Soon the DC current starts transferring to the transformer secondary but the current controller cancels the same and hence the sensor output goes to zero fast, within about 0.5 second. It may also be noted here that the actual output of a practical sensor may not exceed about $15 \mathrm{~V}$ due to saturation but in any case we have limited the same to $\pm 3 \mathrm{~V}$ making it irrelevant. Figure 32 shows the DC current injected to the load by the power electronic converter which is settled at $1 \mathrm{~A}$ after the brief transient. Figure 33 shows the final current in the transformer secondary, which is the load current waveform without the DC component of $1 \mathrm{~A}$.

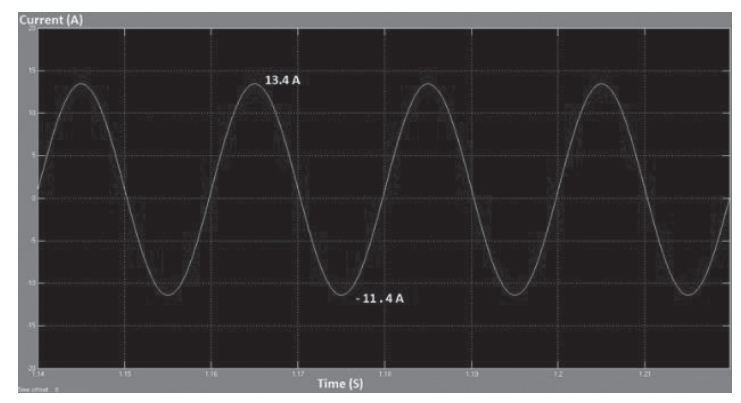

Figure 30- Load current waveform with 1A DC on top of $90 \%$ AC current

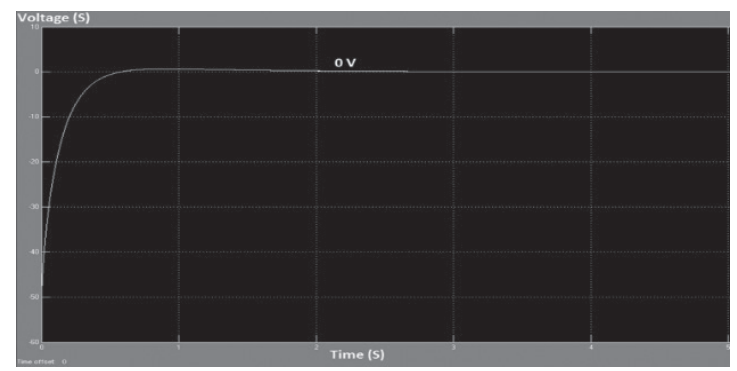

Figure 31- Output of DC current sensor

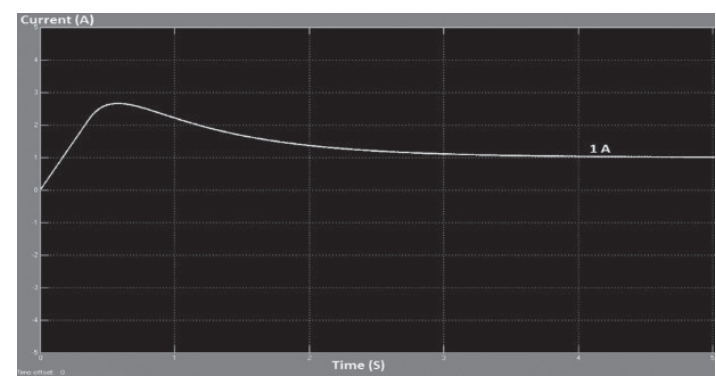

Figure 32- DC current injected to load by the power electronic converter 


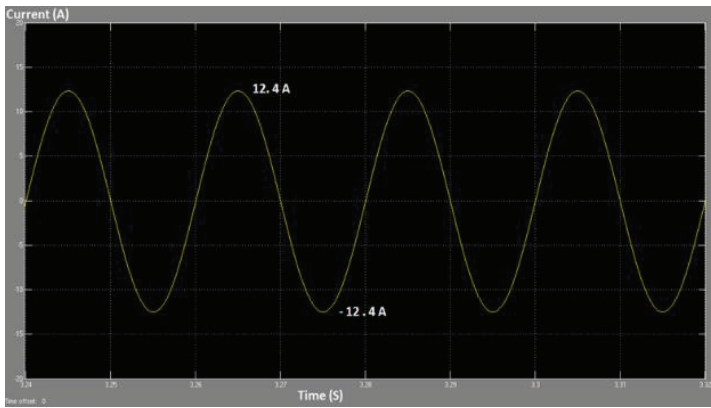

Figure 33- Final current in the transformer secondary

It can be observed that the final transformer current is now the $90 \%$ resistive load current (with equal positive and negative half-cycles) without the 1A DC component.

d) Case of -1 A step DC current in the load produced by an ideal DC source at the load

Figure 34 shows the schematic of the system that was simulated. The $45 \Omega$ resistive load established $90 \%$ load current, and the ideal DC current source introduced -1 A DC current in to the load (notice that the current source is now acts in reverse direction).

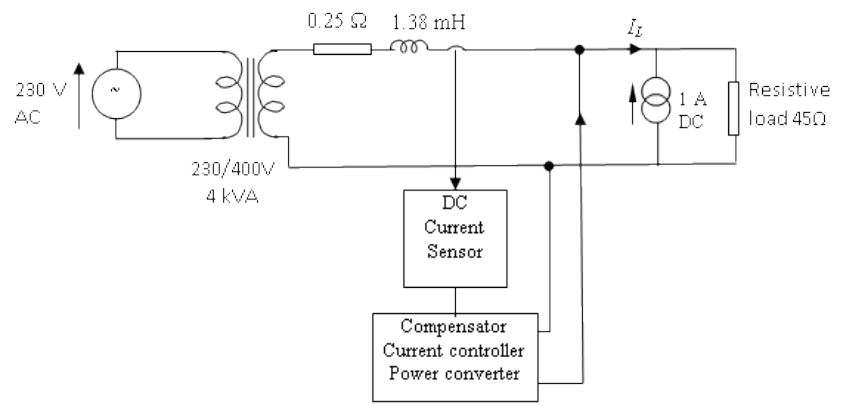

Figure 34- System schematic for -1A step DC current in the load produced by an ideal current source

Figure 35 shows the output of the DC current sensor. The sensor response has now gone to $45 \mathrm{~V}$ at the beginning due to the same reasons given in section (c) above. DC current has then transferred to the transformer secondary but the current controller has canceled the same and the sensor output has gone to zero accordingly, within about 0.5 second. Figure 36 shows the DC current injected to the load by the power electronic converter which is settled at -1 A after the brief transient. Figure 37 shows the final current in the transformer secondary, which is the load current waveform without the DC component of $-1 \mathrm{~A}$. It can be observed that the final current in the transformer secondary is now the $90 \%$ resistive load current (with equal positive and negative half-cycles) without the 1A DC component.

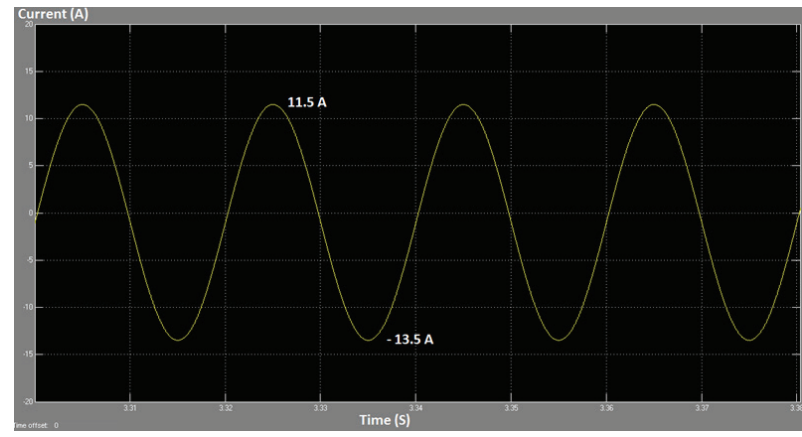

Figure 35- Load current waveform with -1A DC on top of $90 \%$ AC current

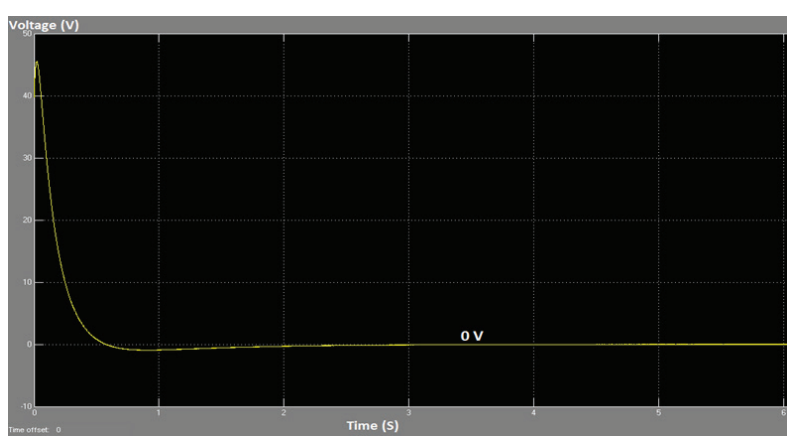

Figure 36- Output of DC current sensor

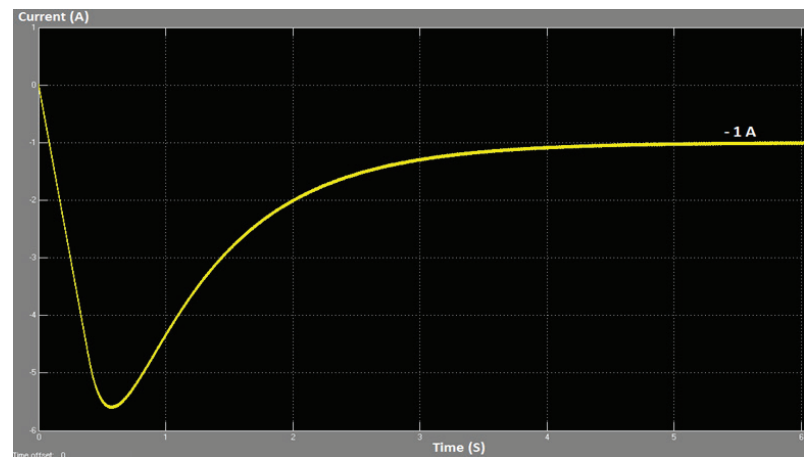

Figure 37- DC current injected to the load by the power electronic converter

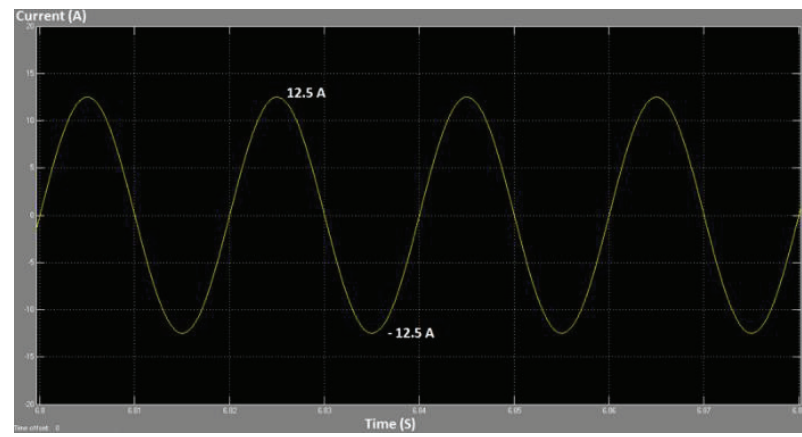

Figure 38- Final current in the transformer secondary

In summary, the results of simulation show that the DC current in the transformer secondary has been eliminated completely in all cases of loadinjected DC current. 


\section{Conclusion}

This paper has described the development of a very satisfactory DC offset elimination system for a distribution transformer. DC current reaching at the secondary side of the transformer was completely absorbed in to a current controlled converter. Preliminary investigations revealed the severity of the effects due to DC current in a transformer emphasizing the need for elimination. A critical requirement in the development of the system was an accurate current sensor to detect small DC current mixed up with large AC current and the authentic current sensor developed and described in the paper solved the problem. This sensor can be used in many similar other applications. Considering the future growth of non-linear loads, grid-tie inverters and power electronic intensive loads in utility system, the DC current elimination will be an ever pressing need for most of the future distribution transformers.

\section{Acknowledgement}

Author wishes to acknowledge the Head of the Department of Electrical Engineering at the University of Moratuwa for providing resources to conduct the research. Further authors extend gratitude to General Sir John Kotelawala Defence University for the support and facilities provided.

\section{References}

1. Karunadasa, J. P., Herath, H. M. A. I., “Investigation of the effects of DC current at the point of common coupling on the operation of distribution transformers", Proceedings of the 4th International Research conference, General Sir John Kotelawala Defence University, Sri Lanka, August 2016.

2. Herath, H. M. A. I., Karunadasa, J. P., “Novel Sensor to Measure DC Bias at the Point of Common Coupling of Distribution Transformers", ENGINEER transaction, Institution of Engineers Sri Lanka, to be published.

3. Atkinson, D. J., Blewitt, W. M., Kelly, J., Lakin, R. A., "Approach to low cost prevention of DC injection in transformerless grid connected inverters", IET

Power Electronics, 2010, Vol. 3, Iss.1, pp. 111-119.

4. Ahfock, A., and Bowtell, L., "Direct current offset controller for transformerless single phase photovoltaic grid-connected inverters", IET
Renewable Power Generation, 2010 Vol. 4, Iss.5,

pp.428-437.

5. University of Strathclyde, "DC injection into low voltage AC networks", DTI Commissioned Report, June 2005.

6. Ahfock, T., and Bowtell, L., "DC offset elimination in a single phase grid- connected photovoltaic system", Faculty of Engineering and Surveying, University of Southern Queensland, Australia.

7. Haeberlin, H., Evolution of inverters for grid connected systems from 1989 to 2000, 17th European Photovoltaic Solar Energy Conference, 2001.

8. Armstrong, M., Atkinson, D. J, Johnson, C. M., \& Abeyasekera, T. D., "Auto calibrating DC link current technique for transformerless grid connected H-bridge inverter systems", IEEE Transactions on Power Delivery, Vol. 21, No. 5, September 2006.

9. Alonso, M., Barrado, A., and Chenlo, F., et al (2006) "DC current injection into the network from PV grid inverters", IEEE Transaction on Power Delivery.

10. Giampaolo Buticchi, Emilio Lorenzani, Giovanni Franceschini“ A DC offset current compensation strategy in transformerless grod-connected power converters", IEEE Transactions on Power Delivery, Vol. 26, No. 4, October 2011.

11. Giampaolo Buticchi, \& Emilio Lorenzani, "Detection method of the DC bias in distribution power transformers", IEEE Transactions on Industrial Electronics, Vol. 60, No. 8, August 2013.

12. Fronius International, "High frequency transformer with transformer switchover", https://www.fronius.com/cps/rde/xbcr/SID4725BB5C2C0F62DA/fronius_international/SE_TA_High_Freq uency_Transformer_With_Transformer_Switchover_ EN_320487_snapshot.pdf, Visited, 20 th February 2015.

13. Herath, H. M. A. I., "Load-injected dc current in distribution transformers", M.Sc. dissertation, Dept. Elect. Eng., Moratuwa Univ., Sri Lanka, 2017. 